\title{
The Women in Technology grass roots community at CERN - an example of women networking in a scientific organisation
}

\author{
Maria Alandes Pradillo ${ }^{a}{ }^{*}$ Rachel Bray $^{a}$, Erica Brondolin ${ }^{a}$, Eva Gousiou ${ }^{a}$ and \\ Oksana Shadura ${ }^{b}$ \\ ${ }^{a} C E R N$, \\ 1211 Geneva 23, Switzerland \\ ${ }^{b}$ University Nebraska-Lincoln, \\ 1400 R St, Lincoln, NE 68588, United States \\ E-mails: maria.alandes.pradillo@cern.ch, rachel.bray@cern.ch, \\ erica.brondolin@cern.ch, eva.gousiou@cern.ch and \\ oksana.shadura@cern.ch
}

The creation of scientific knowledge has transitioned from largely solitary work to collective efforts embedded in large collaborations, placing a new emphasis on social networks as the mechanism linking interdependent scientists across departments and universities. Professional networks have proven to be a key contributor in the career success and their presence becomes even more important for under-represented communities. In this context, the Women in Technology community at CERN (WIT) was born in the early 2016. The main aim of the WIT community is to create a supportive network for exchanging experiences and career advice among women working at CERN. WIT activities span on different fronts: networking, mentoring, awareness and outreach. The WIT community today comprises more than 500 members, has organised three mentoring yearly programmes and is present in multiple outreach events, both in the local area and world wide through social media. Women networks, such as WIT, are beneficial to both the network participants and the organisation as a whole: not only do they provide a place to connect and share common experiences but also they can interface with CERN internal programs, such as CERN's official Diversity \& Inclusion, transferring the community's ideas and advocating for minority' issues. It has to be noted that even if WIT was born in the spirit of supporting women, it actually welcomes members from all genders and all CERN's departments. This contribution describes how WIT is structured and the different activities organised by the community; it also highlights how networks like WIT contribute to making an impact on diversity and inclusion in a scientific research organisation like CERN.

The European Physical Society Conference on High Energy Physics (EPS_HEP2021)

26-30 July 2021

Online conference, jointly organized by Universität Hamburg and the research center DESY

"Speaker 


\section{Introduction}

CERN is the European Laboratory for Particle Physics in Geneva, Switzerland. It hosts 15,000 people on site, most of which are physicists and engineers. The Women in Technology community at CERN (WIT) is a grass-roots community started in early 2016. The idea for such community started when several new members of the IT department realized that similar women networks from which they had benefited at university and in industry did not exist at CERN, or even in the local area.

After speaking with like-minded colleagues, they decided to found a group at CERN where colleagues could exchange ideas on common topics and share career advice and experiences. Thus the "Women in Technology at CERN" grass-roots community came on the scene, to complement the other professional community networks within the diverse CERN environment, like LGBTQ network and country networks.

The motivation to create a Women in Technology community at CERN needs to be understood from a bi-dimensional perspective that has to do with both networking and gender.

\section{The Networking Perspective}

The production of scientific knowledge has changed from solitary work to production lab work that places new emphasis on social networks as the mechanism for linking interdependent scientists across departments and universities [1]. Moreover, professional networks are considered a key contributor in the success of professional careers [2]. WIT seeks to benefit from networking opportunities.

\section{The Gender Perspective}

Women at CERN are under-represented, like in many other scientific organisations as shown in the table below.

\begin{tabular}{|c|c|c|c|c|c|c|c|c|c|c|c|c|}
\hline \multirow[b]{2}{*}{ Professional Category } & \multicolumn{4}{|c|}{ Staff Members } & \multicolumn{4}{|c|}{ Fellows } & \multicolumn{4}{|c|}{ MPA (excl. Users) } \\
\hline & $\mathrm{F}$ & $M$ & Total & $\%$ & $\mathrm{~F}$ & M & Total & $\%$ & $\mathrm{~F}$ & $M$ & Total & $\%$ \\
\hline 1. Research Physicists & 10 & 73 & 83 & 3.15 & 22 & 73 & 95 & 12.57 & 118 & 706 & 824 & 48.84 \\
\hline$\%$ & 12.05 & 87.95 & 100 & & 23.16 & 76.84 & 100 & & 14.32 & 85.68 & 100 & \\
\hline 2. Scientific \& Eng. work & 142 & 1,046 & 1,188 & 45.09 & 107 & 406 & 513 & 67.86 & 179 & 552 & 731 & 43.33 \\
\hline$\%$ & 11.95 & 88.05 & 100 & & 20.86 & 79.14 & 100 & & 24.49 & 75.51 & 100 & \\
\hline 3. Technical work & 53 & 788 & 841 & 31.92 & 15 & 88 & 103 & 13.62 & 6 & 64 & 70 & 4.15 \\
\hline$\%$ & 6.30 & 93.70 & 100 & & 14.56 & 85.44 & 100 & & 8.57 & 91.43 & 100 & \\
\hline 4. Manual work & 2 & 51 & 53 & 2.01 & & & & & 2 & 15 & 17 & 1.01 \\
\hline$\%$ & 3.77 & 96.23 & 100 & & & & & & 11.76 & 88.24 & 100 & \\
\hline 5a. Prof. Admin. work & 97 & 93 & 190 & 7.21 & 28 & 9 & 37 & 4.89 & 10 & 10 & 20 & 1.19 \\
\hline$\%$ & 51.05 & 48.95 & 100 & & 75.68 & 24.32 & 100 & & 50.00 & 50.00 & 100 & \\
\hline $5 b / 5 c$. Office and Admin. work & 243 & 37 & 280 & 10.63 & 7 & 1 & 8 & 1.06 & 23 & 2 & 25 & 1.48 \\
\hline$\%$ & 86.79 & 13.21 & 100 & & 87.50 & 12.50 & 100 & & 92.00 & 8.00 & 100 & \\
\hline Total & 547 & 2,088 & 2,635 & 100 & 179 & 577 & 756 & 100 & 338 & 1,349 & 1,687 & 100 \\
\hline
\end{tabular}

Figure 1: CERN Personnel Statistics 2020 - MPA means “Associated members of personel" 
The low participation of women in science has been studied and analysed extensively. Although worldwide women are actively pursuing bachelor's and master's degrees and even outnumber men at these levels, since they represent $53 \%$ of graduates, their numbers drop off abruptly at $\mathrm{PhD}$ level. Suddenly, male graduates (57\%) overtake women. The discrepancy widens at the researcher level, with men now representing $72 \%$ of the global pool [3]. In the $\mathrm{EU}$, the proportion of women in the information science technology (IST) and digital workforce is $13 \%$ [4]. WIT aims at helping those women who are in the minority at CERN and may feel isolated, to connect with other women and benefit from those contacts at personal and professional level.

Moreover, women networks bring many benefits to both the network participants and the organisation: they create community, providing a place to connect, communicate and share about common experiences; they're a great way to find a mentor; they help build confidence, leading women to take on challenges and opportunities that they perhaps wouldn't have otherwise; they inspire, as often it is common that senior women share stories and lessons on how they have navigated and overcome challenges in their professional career. In addition, women networking can help reducing the gender gap [5] [6]. It has to be noted that even if WIT was born in the spirit of supporting women, it actually welcomes members from all genders and all technical fields.

\subsection{WIT Organisers and Community}

WIT is an open community for people working at CERN who can subscribe to a mailing list and receive regular news on upcoming events. The mailing list currently counts on more than 500 members.

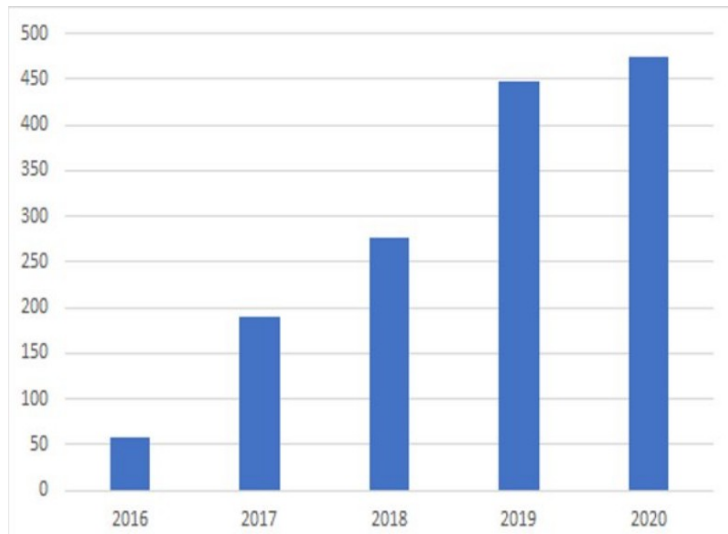

Figure 2: WIT Mailing list membership. In September 2021 there were 509 members

This mailing list is managed by the WIT Steering Committee, who is currently composed of five members, all women working in different departments at CERN. All of them are involved on a voluntary basis. Internal discussion channels are also available for members of the 
community who would like to share useful links and information. WIT Steering Committee keeps regular contact with the CERN Diversity and Inclusion Office and participates in their regular round tables with other CERN community networks.

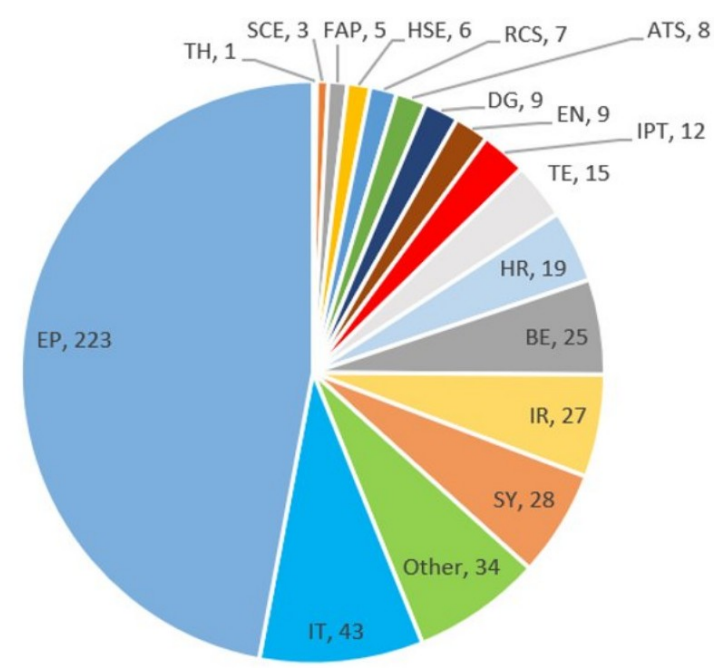

Figure 3: WIT mailing list membership per department : Physicists (EP, TH), Engineers (IT, EN, SY, BE, TE, ATS, HSE, RCS) and Administration (FAP, DG, IPT, HR, IR)

\subsection{WIT Activities}

WIT organises a broad range of activities. These activities are in general coordinated and organised by the steering committee. Outreach and mentoring are coordinated by dedicated teams. All the effort is based on voluntary work and we also count on the involvement and engagement of many members of the community.

\subsubsection{WIT Talks}

WIT Talks are basically interviews to exchange and debate with senior colleagues. They used to happen at CERN but moved to an online format after the pandemic. In many cases, recordings of these talks are internally available for CERN colleagues. When happening in person at CERN, they were followed up by a networking lunch. There are actually two types of talks:

- WIT Talks: they are interviews with women in leading roles at CERN, in industry or in academia who share about their careers and backgrounds, personal and professional challenges.

- WIT Diversity Talks: they are interviews with senior male colleagues who talk around their experiences and thoughts on gender diversity and gender balance, and why this has been important to them both professionally and personally.

Since 2016, WIT has organised 22 interviews with senior women working at CERN, 7 interviews with women working in industry and 5 interviews with women working in academia. WIT has also organised 6 Diversity Talks. 


\subsubsection{WIT Drinks and Coffees}

WIT Drinks are networking events where participants have the opportunity to meet other colleagues at CERN and listen to the experts of the different experiments and departments. It started as a pure networking event in the cafeteria and it quickly evolved to an opportunity to discover CERN too. We have visited in total 14 locations including experiments, facilities and lab visits. In most cases the visits are guided by women experts and still are followed up by a network drink.

WIT Coffees is a new activity started in 2021 and it targets newcomers to the CERN site. Although WIT is present in the official On Boarding sessions organised by the Human Resources department at CERN, we still offer interested people to meet in small groups. WIT has organised 3 online sessions in 2021 and as soon as it is possible, WIT Coffees will be organised face to face on CERN site.

\subsubsection{WIT Outreach}

STEM outreach activities have become very popular in the past years [7]. Political and social awareness on the need for more STEM graduates [8] have put the promotion of science in the agenda of many schools, but also museums and scientific organisations like CERN [9]. CERN already has a wide and rich program of outreach and public engagement events, including on site visits, exhibitions, lectures and involvement in many events in the local area [10]. CERN personnel is welcome and encouraged to get involved in these events. Public engagement and outreach activities are very rewarding and allow to take research out of the lab and academic environment, and showcasing it to a public audience.

On top of all this, a new gender lens has been given to the ongoing efforts to promote science in order to close the gender gap in STEM. Examples of this are the International Day of Women and Girls in Science on $11^{\text {th }}$ February [11] and the International Girls in ICT Day on $25^{\text {th }}$ April [12]. There are also many other initiatives to promote science among girls like Django Girls [13] or Girls who Code [14] for computing, Engineer girl [15] for engineering or STEM like a girl [16] for STEM in general. It is an opportunity for WIT to contribute to CERN outreach activities, and in particular those ones targeting girls, by bringing the perspective of female physicists and engineers and promoting female role models in STEM.

Moreover, WIT decided to develop workshops for younger kids, which so far were not available in the existing CERN outreach offer. Studies show that kids decide to pursue STEM studies as early as high-school and college [17]. WIT has been very active in the past years developing workshops and activities for primary school kids, high-school kids and also families. Some examples are programming workshops for children and teenagers, and other activities to bring particle physics closer to young kids and families. More information is available in https://cern.ch/wit/outreach/.

\subsubsection{WIT Mentoring}

Effective mentorship has an overall positive effect on academic achievement, retention, and degree attainment, as well as on career success, career satisfaction, and career commitment [18]. A mentoring program was put in place in 2018 following the demands of the WIT 
community [19]. The program is open to everyone and it is organised once per year. 25 senior male and female colleagues are part of the pool of mentors and are matched every year to one single mentee. Mentees describe their mentoring goals in their application form and the mentoring committee matches the pairs based on the provided information. Some goals might include: improving communication skills, building confidence and interpersonal skills, receiving experience-based knowledge and advice, guidance on professional development or creating a pathway to personal and professional growth. Mentees can choose to work with mentors from the same department or from elsewhere, including CERN Alumni, as the mentoring program is done in collaboration with the CERN Alumni Network. Two individual checkpoints are done throughout the mentoring exercise and a final survey is carried out at the end to gather feedback from participants.

During the past editions, WIT had the chance to count on the collaboration of mentoring experts in the area, like University of Geneva [20], but also liaised with other experts like the Dynament program organised by DESY [21]. In 2021, a specific training module for mentors and mentees was organised in collaboration with CERN Learning and Development group.

\subsubsection{Lectures, Screenings and External Contacts}

WIT also organises other events like lectures and movie screenings. WIT is in touch with similar initiatives in other organisations and companies (like Rights Tech Women or Swiss Tech Ladies), and has also organised exchanges and visits through these contacts.

\subsubsection{Social Media}

WIT is present in social media via Instagram since 2019 (@wit.at.cern) and through a new web page launched in 2019 (https://cern.ch/wit). The goal is to reach out to younger women outside CERN, promoting and showcasing female role models at CERN and in science in general. It also allows for collaboration with journals, artists and other research groups.

\subsubsection{WIT Newsletter}

Friday Links is the weekly newsletter containing links to events, news, articles, pictures, movies, books and videos featuring women in science, feminism, gender equality, equal opportunities and any other topic relevant to the community.

\subsection{Summary}

Over the years, WIT has successfully set up a structured and consolidated grassroots community that aims at gathering people interested in gender equality within CERN and beyond, with an open spirit, in an informal but engaged way. The main contributions of WIT are: raise awareness on gender issues, connect people interested in equal opportunities, stimulate exchange about gender equality, provide mentoring and community support, showcase female role models and inspire the next generations.

\section{References}

[1] Etkowitz H, Kemelgor C, Uzzi B, The Advancement of Women in Science and Technology, 2000 
[2] Lou Adler, New Survey Reveals 85\% of All Jobs are Filled Via Networking, 2016, https://www.linkedin.com/pulse/new-survey-reveals-85-all-jobsfilled-via-networking-lou-adler/

[3] 2015, UNESCO Science Report: towards 2030, https://unesdoc.unesco.org/ark:/48223/pf0000235406

[4] European Commission, Wanted: more women in science and technology, 2020, https://ec.europa.eu/eurostat/web/products-eurostat-news/-/EDN20200210-2

[5] Shawn Achor, Do Women's Networking Events Move the Needle on Equality?, 2018, https://hbr.org/2018/02/do-womens-networking-events-move-theneedle-on-equality

[6] UNESCO, Strengthening networks of women scientists worldwide, http://www. unesco.org/new/en/natural-sciences/priority-areas/gender -and-science/supporting-women-scientists/strengthening-networks-ofwomen-scientists/

[7] Grace Chen, 2019, https://www.publicschoolreview.com/blog/the-risingpopularity-of-stem-a-crossroads-in-public-education-or-a-passingtrend

[8] European Commission, Science Education, Horizon 2020, https://ec.europa.eu/programmes/horizon2020/en/h2020-section/scienc e-education

[9] CERN Science Gateway, https://home.cern/news/press-release/knowledgesharing/cern-unveils-its-science-gateway-project

[10] CERN and its neighbours, https://voisins.cern/en

[11] United Nations, International Day of Women and Girls in Science, https://www. un.org/en/observances/women-and-girls-in-science-day

[12] International Telecommunications Union, International Girls in ICT Day, https://www.itu.int/en/ITU-D/Digital-Inclusion/Women-and-Girls/Girl s-in-ICT-Portal/Pages/Portal.aspx

[13] Django Girls, https://djangogirls.org/

[14] Girls who Code, https://girlswhocode.com/

[15] Engineer Girl, https://www.engineergirl.org/

[16] STEM like a girl, http://stemlikeagirl.org/

[17] Microsoft Corporation, STEM Perceptions: Student \& Parent StudyParents and Students Weigh in on How to Inspire the Next Generationof Doctors, Scientists, Software Developers and Engineers, 2011, https://news.microsoft.com/download/archived/presskits/citizenship/ docs/STEMPerceptionsReport.pdf

[18] The Science of Effective Mentorship in STEMM. National Academies of Sciences, Engineering, and Medicine; Policy and Global Affairs; Board on Higher Education and Workforce; Committee on Effective Mentoring in STEMM; Dahlberg ML, Byars-Winston A, editors. Washington (DC): 2019 Oct 30. https://www.ncbi.nlm.nih.gov/books/NBK552775/ 
[19] Mentoring Programme Pilot within the Women in Technology Network- Maria Alandes - March 2018, https: / / cernbox.cern. ch/index . php/s/NOjB7u3fGUO4hgT

[20] Mentorat Releve - Service Egalite et Diversite - Universite de Geneve:

https://www. unige.ch/rectorat/egalite/programmes-et-formations/prog rammes/mentorat-releve/

[21] Mentoring for women in natural sciences - DESY and Hamburg University: https://www.dynament.de/ 